literacy, willingness to change treatment, or decisional conflict. We found a significant improvement in pre-post willingness to change treatment in intervention vs. control participants ( 0.5 vs $0.01, p=0.01)$. We calculated an effect size (Glass's delta) for the intervention of 0.48 (i.e. moderate). Moreover, decisional conflict about treatment change decreased; there was no significant difference in pre-post differences in decision conflict between groups.

Conclusion: This randomized trial testing a novel patient-directed intervention advocating for T2T strategy implementation in RA care increased self-reported willingness to change RA treatment. Further studies are needed to evaluate if this effect is sustained over time and if it translates into actionable behavior change.

Disclosure of Interests: Maria Danila Grant/research support from: Pfizer, Inc., Consultant for: Sanofi Genzyme \& Regeneron, Lang Chen: None declared, Justin Owensby: None declared, Ronan O'Beirne Grant/research support from: Pfizer, Inc., Josh Melnick: None declared, Eric Ruderman Consultant for: Pfizer Inc., Leslie Harrold Shareholder of: Corrona, Grant/ research support from: Pfizer, Consultant for: AbbVie, BMS, and Genentech, Employee of: Corrona, Jeffrey Curtis: None declared DOI: 10.1136/annrheumdis-2019-eular.4292

\section{THU0115 IS INCIDENT RHEUMATOID ARTHRITIS INTERSTITIAL LUNG DISEASE ASSOCIATED WITH METHOTREXATE TREATMENT? RESULTS FROM A MULTIVARIATE ANALYSIS IN THE ERAS AND ERAN INCEPTION COHORTS:}

KIELY Patrick ${ }^{1}$, Amanda Busby ${ }^{2}$, Elena Nikiphorou ${ }^{3}$, Keith Sullivan ${ }^{2}$ Adam Young ${ }^{2} .{ }^{1}$ St George's University Hospitals NHS Foundation Trust, Rheumatology, London, United Kingdom; ${ }^{2}$ University of Hertfordshire, Center for Health Services and Clinical Research and Post Graduate Medicine, Hatfield, United Kingdom, ${ }^{3}$ King's College, London, Academic Rheumatology, London, United Kingdom

Background: Rheumatoid arthritis interstitial lung disease (RA-ILD) is a rare but significant manifestation of RA, with high mortality. Methotrexate (MTX) is known to cause hypersensitivity pneumonitis, but its effect on the onset of RA-ILD is less clear.

Objectives: To assess predictive factors for rheumatoid arthritis interstitial lung disease (RA-ILD) in two early RA inception cohorts with a focus on MTX exposure.

Methods: Patients with new diagnosis of RA recruited to the early RA study (ERAS) and the early RA network (ERAN). Standardised data including demographics, drug therapies and clinical outcomes including the presence of RA-ILD were collected at baseline, within 3- 6 months, at 12 months and annually for up to 25 years thereafter. Primary outcome was the association of MTX exposure with incident RA-ILD. Secondary outcomes were the association of demographic, comorbid and RA specific factors on incident RA-ILD using univariate and multivariate analyses and the association of MTX exposure on time to RA-ILD diagnosis using time to event Cox proportional hazards analysis.

Results: Of 92 eligible ILD cases, 39 occurred in 1578 (2.5\%) MTX exposed and 53 in $1114(4.8 \%)$ non-MTX exposed cases. The primary analysis of incident RA-ILD cases only developing after any CSDMARD treatment $(n=67)$ showed MTX exposure not to be associated with incident RA-ILD (O.R. $0.85 \mathrm{Cl} 0.49,1.49 \mathrm{p}=0.578$ ) and a non-significant trend for delayed ILD diagnosis (O.R. $0.54 \mathrm{Cl} 0.28,1.06 \mathrm{p}=0.072$ ) (see Figure). In an extended analysis including all RA-ILD cases ( $n=92$, including those present pre csDMARD exposure), MTX exposure was associated with a significantly reduced risk of incident RA-ILD (O.R. $0.48, \mathrm{Cl}$ $0.3,0.79 \mathrm{p}=0.004$ ) and longer time to ILD diagnosis (O.R. 0.41, Cl 0.23, $0.75 \mathrm{p}=0.004)$. Other independent baseline associations with incident RAILD were higher age of RA onset, ever smoking, male gender, rheumatoid nodules and longer time from first RA symptom to first out-patient visit (see Table).

Table Multivariate logistic analysis showing co-variates independently associated with RAILD development

\begin{tabular}{|c|c|c|c|c|}
\hline & $\begin{array}{l}\text { Primary analysis, RA-ILD } \\
\text { onset after any csDMARD } \\
\text { exposure, } n=67\end{array}$ & $\begin{array}{c}\text { Wald } \\
\text { test }\end{array}$ & $\begin{array}{l}\text { Extended cohort, including } \\
\text { RA-ILD onset pre any } \\
\text { csDMARD, } n=92\end{array}$ & $\begin{array}{l}\text { Wald } \\
\text { test }\end{array}$ \\
\hline & O.R. (95\% C.I.) & $p$ value & O.R. (95\% C.I.) & $p$ value \\
\hline $\begin{array}{l}\text { Methotrexate } \\
\text { exposure }\end{array}$ & $0.85(0.49,1.49)$ & 0.578 & $0.48(0.3,0.79)$ & 0.004 \\
\hline Age RA & $1.04(1.02,1.06)$ & $<0.001$ & $1.04(1.02,1.06)$ & $<0.001$ \\
\hline
\end{tabular}

Age RA

$1.04(1.02,1.06)$

$<0.001$

$<0.001$

\begin{tabular}{lcccc}
$\begin{array}{l}\text { Smoking, } \\
\text { ever, } \\
\text { baseline }\end{array}$ & $2.21(1.21,4.03)$ & 0.01 & $1.91(1.13,3.25)$ & 0.016 \\
$\begin{array}{l}\text { Male gender } \\
\text { RF positive, }\end{array}$ & $1.44(0.83,2.48)$ & 0.193 & $1.74(1.05,2.86)$ & 0.03 \\
$\begin{array}{l}\text { baseline } \\
\text { RA nodules, }\end{array}$ & $2.02(1.07,3.82)$ & 0.029 & & n.s. \\
$\begin{array}{l}\text { baseline } \\
\text { Onset }-1^{\text {st }}\end{array}$ & $1.04(1.00,1.07)$ & 0.027 & $1.03(1.0,1.07)$ & 0.04 \\
$\begin{array}{l}\text { OPD } \\
\text { Baseline }\end{array}$ & $0.62(0.40,0.95)$ & 0.027 & $0.67(0.46,0.98)$ & 0.037 \\
$\begin{array}{l}\text { major co- } \\
\text { morbidities }\end{array}$ & & & & \\
$\begin{array}{l}\text { Baseline } \\
\text { ESR }\end{array}$ & - & n.s. & $1.01(1.0,1.02)$ & 0.047 \\
\hline
\end{tabular}

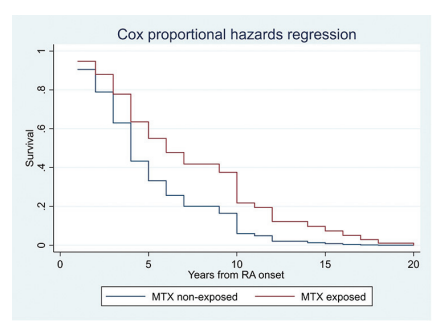

Abstract THU0115 - Figure 1. Cox proportional time to event analysis showing time of onset of RA-ILD from first joint symptoms of RA in MTX exposed and non-MTX exposed groups; primary analysis: cases with RA-ILD first recorded after any csDMARD exposure, $\mathrm{n}=67$.

Conclusion: In ERAS/ERAN, incident RA-ILD is significantly associated with older age of RA onset, ever smoking, nodules, RF positivity, male gender, ESR, and a longer time from first RA symptoms to first secondary care visit. There is no association between MTX treatment and incident RA-ILD. MTX may have a protective role in delaying the onset of RA-ILD.

Acknowledgement: All recruiting ERAS and ERAN centers

Disclosure of Interests: Patrick KIELY Paid instructor for: Amgen, Gilead, BMS, Speakers bureau: Abbvie, BMS, UCB, Lilly, Pfizer, Amanda Busby: None declared, Elena Nikiphorou: None declared, Keith Sullivan: None declared, Adam Young: None declared

DOI: 10.1136/annrheumdis-2019-eular.3952

\section{THU0116 COMPARATIVE SAFETY OF BIOLOGIC DMARDS AND ABATACEPT IN RHEUMATOID ARTHRITIS WITH COPD: A REAL-WORLD POPULATION-BASED OBSERVATIONAL STUDY}

Samy Suissa ${ }^{1}$, Marie Hudson ${ }^{1}$, Pierre Ernst ${ }^{1}$, Sophie Shen ${ }^{2}$, Teresa Simon ${ }^{2}$. ${ }^{1}$ McGill University, Montreal, Canada; ${ }^{2}$ Bristol-Myers Squibb, New Jersey, United States of America

Background: The biologic DMARD abatacept has been associated with respiratory adverse events in patients with RA who have chronic obstructive pulmonary disease (COPD) in the ASSURE trial (NCT00048932) based on only 54 patients with $\mathrm{RA}$ and COPD. ${ }^{1} \mathrm{~A}$ large observational study of patients with RA and COPD, involving over 1,800 patients using abatacept did not find an increased incidence of respiratory adverse events with abatacept compared with other biologic DMARDs. ${ }^{2}$ it remains uncertain, however, whether this potential respiratory risk affects all biologic DMARDs, including abatacept, when compared with non-biologic DMARDs.

Objectives: To assess in a real-world observational setting whether patients with RA and COPD treated with biologic DMARDs, including abatacept, have an increased risk of serious respiratory adverse events compared with similar patients treated with non-biologic DMARDs.

Methods: The Truven MarketScan ${ }^{\oplus}$ Commercial and Supplemental Medicare databases were used to identify patients diagnosed with RA and COPD, treated with a biologic or non-biologic DMARD between January 2007 and December 2015. A prevalent new-user cohort design was used to match each new user of a biologic DMARD with a new user of a non-biologic DMARD on time-conditional propensity scores. ${ }^{3}$ Patients were followed up from new use until the end of enrolment or 31 December 2015. The Cox model was used to estimate the hazard ratios (HRs) of respiratory adverse events associated with biologic DMARDs compared 
with non-biologic DMARDs, further adjusted for confounders found to be unbalanced despite matching on propensity scores.

Results: The study cohort included 7,424 new users of biologic DMARDs matched to 7,424 new users of non-biologic DMARDs, followed for up to 9 years. The adjusted $\mathrm{HR}(95 \% \mathrm{Cl})$ of the combined respiratory endpoint, including severe COPD exacerbation, bronchitis and severe pneumonia or influenza, with biologic DMARD use relative to non-biologic DMARDs was 1.06 (0.91-1.24). For severe COPD exacerbation it was 0.88 (0.64-1.21), $1.02(0.82-1.27)$ for bronchitis, while for pneumonia or influenza it was $1.18(0.90-1.54)$ if hospitalized and $1.01(0.89-1.14)$ as outpatient. For users of abatacept relative to non-biologic DMARDs, the HR of the combined respiratory endpoint was 1.06 (0.80-1.42). Results remained unchanged with sensitivity analyses.

Conclusion: In this large real-world study of patients with RA and COPD, the risk of pre-specified serious respiratory adverse events was not significantly increased in patients using biologic DMARDs, and specifically abatacept, compared with those using non-biologic DMARDs. This study does not support the safety signal for abatacept from the ASSURE trial.

\section{REFERENCES:}

[1] Weinblatt E, et al. Arthritis Rheum 2006;54:2807-16.

[2] Suissa S, et al. Ann Rheum Dis 2018;77:613-614.

[3] Suissa A, et al. Pharmacoepidemiol Drug Saf 2017;26:459-68.

Disclosure of Interests: Samy Suissa Grant/research support from: Advisory board meetings, or as speaker, or received research grants from AstraZeneca, Bayer, Boehringer-Ingelheim, Bristol-Myers Squibb, Novartis, Speakers bureau: Advisory board meetings, or as speaker, or received research grants from AstraZeneca, Bayer, Boehringer-Ingelheim, BristolMyers Squibb, Novartis, Marie Hudson Grant/research support from: Unrestricted research funds from Bristol-Myers Squibb, Pierre Ernst: None declared, Sophie Shen Employee of: Bristol-Myers Squibb, Teresa Simon Employee of: Bristol-Myers Squibb

DOI: 10.1136/annrheumdis-2019-eular.1607

\section{THU0117 PHARMACOKINETICS AND SHORT-TERM SAFETY OF FILGOTINIB, A SELECTIVE JANUS KINASE 1 INHIBITOR, IN SUBJECTS WITH MODERATE HEPATIC IMPAIRMENT}

Kacey Anderson, Hao Zheng, Oliver Medzihradsky, LI Yizhao, Ann Qin, Brian Kearney, Anita Mathias. Gilead Sciences, Inc., Foster City, United States of America

Background: Filgotinib (FIL) is an oral selective Janus kinase 1 (JAK1) inhibitor being developed to treat inflammatory diseases.

Objectives: This phase 1 study evaluated the pharmacokinetics (PK) and short-term safety of FIL in subjects with hepatic impairment $(\mathrm{HI})$ to guide safe and appropriate dosing in the presence of this comorbidity.

Methods: This study enrolled 20 subjects: 10 with moderate (Child-Turcotte-Pugh-B) $\mathrm{HI}$ and 10 healthy controls. All were matched for age, sex, and body mass index and received a single oral dose of FIL $100 \mathrm{mg}$ followed by intensive plasma PK sampling over 120 hours. Plasma concentrations of FIL and its primary circulating metabolite were measured by validated LC-MS/MS methods; plasma protein binding was also evaluated. A parametric analysis of variance was applied to the natural logarithmic transformation of $\mathrm{PK}$ parameters ( $\mathrm{AUC}$ and $\mathrm{C}_{\max }$ ) for $\mathrm{FIL}$ and its metabolite. Geometric least squares means (GLSM) ratios and $90 \%$ confidence intervals (Cls) of PK parameters were evaluated in subjects with moderate $\mathrm{HI}$ relative to controls, with clinically relevant exposure change defined as $\geq 2$-fold for FIL or its metabolite. Safety endpoints consisted of the incidence of adverse events (AEs), laboratory abnormalities, and vital sign and electrocardiogram changes monitored through day 15

Results: All subjects completed the protocol-specified dosing and assessments. FIL and metabolite AUCs were increased by 1.6- and 1.2-fold, respectively, in subjects with moderate $\mathrm{HI}$ compared to controls. Protein bindings of FIL and its metabolite $\left(f_{u}: 41 \%-44 \%\right.$ and $55 \%-61 \%$, respectively) were unchanged in subjects with moderate HI. FIL was well tolerated, with no serious AEs reported. All treatment-emergent AEs were Grade 1 in severity. Serum and plasma markers did not show evidence of treatment-emergent hepatotoxicity or worsened liver function and were consistent with the use of $\mathrm{FIL}$ in a population with moderate $\mathrm{HI}$.

Conclusion: In the setting of moderate HI, a single oral dose of FIL 100 mg was well tolerated. FIL can be administered without predefined dose adjustment to patients with mild to moderate $\mathrm{HI}$.

Disclosure of Interests: Kacey Anderson Shareholder of: Gilead Sciences, Inc., Employee of: Gilead Sciences, Inc., Hao Zheng Shareholder of:
Gilead Sciences, Inc., Employee of: Gilead Sciences, Inc., Oliver Medzihradsky Shareholder of: Gilead Sciences, Inc., Employee of: Gilead Sciences, Inc., Yizhao Li Shareholder of: Gilead Sciences, Inc., Employee of: Gilead Sciences, Inc., Ann Qin Employee of: Gilead Sciences, Inc., Brian Kearney Employee of: Gilead Sciences, Inc., Anita Mathias Shareholder of: Gilead Sciences, Inc., Employee of: Gilead Sciences, Inc.

DOI: 10.1136/annrheumdis-2019-eular.2325

\section{THU0118 TREATMENT OF RHEUMATOID ARTHRITIS WITH COMBINATION THERAPY USING A BIOLOGIC AGENT AND METHOTREXATE LOWERS THE RISK OF DECREASING KIDNEY FUNCTION COMPARED TO METHOTREXATE MONOTHERAPY}

MIWA YUSUKE, Nobuyuki Yajima, Sakiko Isojima, Ryo Yanai, Mika Hatano, Yoko Miura, Nao Oguro, Tomoki Hayashi, Kosuke Sakurai, Tsuyoshi Kasama. Showa University School of Medicine, Division of Rheumatology, Department of Medicine, Tokyo, Japan

Background: Rheumatoid arthritis (RA) is associated with reduced kidney function, possibly due to chronic inflammation or the use of nephrotoxic therapies. However, little is known about the effects of novel non-nephrotoxic biologic agents (biological disease-modifying antirheumatic drugs [bDMARDs]) on the risk of decreasing kidney function.

Objectives: To elucidate the effects of bDMARDs on decreasing kidney function.

Methods: We recruited a cohort of 1058 patients with RA from the All Showa University of RA database. The following background factors were analyzed: age, sex, type of bDMARD, methotrexate and prednisolone dosages, use of conventional synthetic DMARDs and nonsteroidal antiinflammatory drugs, body mass index, smoking history, diabetes status hypertension status, dyslipidemia status, serum creatinine $(\mathrm{Cr})$ level, CRP level, and matrix metalloproteinase-3 level. Furthermore, we used the simplified disease activity index (SDAl) for the evaluation of the disease activity of RA. The estimated glomerular filtration rate (eGFR) was calcu lated using the serum $\mathrm{Cr}$ level, age, and sex. We divided the patients into two groups according to the treatment, as follows: bDMARD with methotrexate (MTX) treatment (combination) group (744 patients) and MTX monotherapy group (314 patients). The patients followed the same treatment plan for 1 year. Patients who had primary and secondary failures, adverse effects of drugs, and missing data and those who relocated or withdrew from the study were excluded. Propensity scores were calculated based on the following factors: age, sex, prednisolone dosage, MTX dosage, SDAI, Cr level, eGFR, diabetes status, hypertension status and dyslipidemia status. Overall, 285 patients in each group were identified by propensity score matching. The primary end-points were the eGFR values before treatment and 6 months and 1 year after treatment. Significance was determined using the repeated-measures analysis of variance (ANOVA).

Results: The eGFR $\left(\mathrm{mL} / \mathrm{min} / 1.73 \mathrm{~m}^{2}\right)$ decreased from $88.5 \pm 21.8$ to $86.1 \pm 21.5$ and $83.7 \pm 21.0$ at 6 months and 1 year, respectively, in the combination treatment group and from $86.3 \pm 37.9$ to $79.5 \pm 19.1$ and $78.5 \pm 19.5$ at 6 months and 1 year, respectively, in the MTX monotherapy group. No interaction was observed between the groups. A significant difference was observed between the groups $(p=0.0066)$ and even during the treatment period $(p<0.001)$ by repeated-measures ANOVA.

Conclusion: The decrease in eGFR was smaller in the combination treat ment group than in the MTX monotherapy group. bDMARD use may lower the risk of decreasing kidney function in patients with RA.

Acknowledgement: Cooperation on data collection: All Showa University in Rheumatoid Arthritis (ASHURA) group

Disclosure of Interests: YUSUKE MIWA Grant/research support from: Mit subishi Tanabe Pharma Corporation and AbbVie CK. Astellas Pharma Inc., Mitsubishi Tanabe Pharma Corporation, AbbVie CK, Pfizer Japan Inc., Chugai Pharmaceutical Co., Ltd., Eizai Co., Ltd, Asahi Kasei Pharm Co., Ltd, YL Biologics Ltd., Japan Blood Products Organization, Ono Pharmaceutical Co., Ltd., Nippon Kayaku Co., Ltd., and Teijin Pharma Ltd.

This work was supported by JPJS KAKENHI Grant Number JP17K09324., Nobuyuki Yajima: None declared, Sakiko Isojima: None declared, Ryo Yanai: None declared, Mika Hatano: None declared, Yoko Miura: None declared, Nao Oguro: None declared, Tomoki Hayashi: None declared, Kosuke Sakurai: None declared, Tsuyoshi Kasama: None declared

DOI: 10.1136/annrheumdis-2019-eular.2136 